\title{
Estaciones de Aprendizaje para Abordar Concepciones de Fisiología y Morfología sobre el Concepto de Célula
}

\author{
Learning Stations to Analyze Physiology and Morphology Perceptions of the Cell Concept
}

\author{
Nabil Marzuca-Nassr'; Gabriel Nasri Marzuca-Nassr²; Alejandra Barriga Acevedo ${ }^{3}$ \& Iván R. Sánchez Soto ${ }^{4}$
}

MARZUCA-NASSR, N.; MARZUCA-NASSR, G. N.; BARRIGA, A. A. \& SÁNCHEZ, S. I. R. Estaciones de aprendizaje para abordar concepciones de fisiología y morfología sobre el concepto de célula. Int. J. Morphol., 39(4):1015-1022, 2021.

RESUMEN: El objetivo del presente estudio fue determinar la influencia de la implementación y aplicación de la metodología de enseñanza estaciones de aprendizaje, sobre un aprendizaje activo de la fisiología y morfología de la célula. Se trabajó con 90 estudiantes de enseñanza secundaria, distribuidos en un grupo control y otro experimental, los cuales recibieron clases tradicionales y la aplicación de la metodología estaciones de aprendizaje, respectivamente. Los datos fueron recolectados en base a test de concepciones y conocimientos, más encuesta de valoración. El análisis de los datos reveló que las estaciones de aprendizaje son una metodología de enseñanza efectiva en el aprendizaje de la célula, ya que permiten mejorar significativamente las concepciones previas de los estudiantes, los cuales valoran de manera positiva y significativa la metodología de la que fueron partícipes.

PALABRAS CLAVE: Enseñanza de las ciencias; Enseñanza de la biología; Concepto de la célula; Metodología de enseñanza; Estaciones de aprendizaje.

\section{INTRODUCCIÓN}

En la enseñanza de la Biología, el conocimiento de la fisiología y morfología de la célula es primordial en todos los niveles educativos, ya que ayuda a comprender las acciones integradoras vitales de los seres vivos. Sin embargo, su aprendizaje resulta complejo para los estudiantes, debido a que es muy abstracta, generándose representaciones mentales equivocadas y errores conceptuales en la comprensión de la unidad funcional y estructural de todos los organismos vivos (Caballer \& Giménez, 1993; Rodríguez, 2003; Mengascini, 2006; Herrera \& Sánchez, 2009).

Esta falta de comprensión de la fisiología y morfología de la célula hace necesario buscar otros modos de plasmar su enseñanza, que faciliten su visualización y modelización. Por tal motivo, el momento del desarrollo de la clase debe convertirse en una instancia de aplicación de estrategias diversas que generen mayores posibilidades de acceder al conocimiento, brindando la oportunidad de participar en ambientes originales, flexibles y de trabajo cooperativo, permitiendo que el estudiante construya de manera activa y en diferentes espacios educativos su aprendizaje (Melgar \& Donolo, 2011).
Para ello se implementó y aplicó la metodología de enseñanza estaciones de aprendizaje, en base a una metodología de enseñanza y aprendizaje activo de la fisiología y morfología de la célula, metodología que permite al estudiante acceder de diferentes formas a la información y procesos de aprendizajes, ya sea visuales, auditivos y kinestésicos (VAK), estableciendo "nuevos lugares y/o instancias educativas" (estaciones), donde los estudiantes pueden desarrollar contenidos, habilidades y actitudes, con la finalidad de alcanzar un determinado objetivo de aprendizaje. Permitiendo desarrollar habilidades de pensamiento científico, logrando aprendizajes significativos y mejorando las concepciones previas de los estudiantes (Vieira \& Camero, 2004; Espiñeira, 2005; Ministerio de Educación, 2009; Pinto, 2009; Acevedo et al., 2015), para la construcción de nuevos conocimientos (Motta \& Uyaban, 2016; Triviño \& Tovar, 2017), lo cual genera una motivación individual y colectiva en el trabajo escolar (Rueda \& Piraquive, 2017).

De acuerdo a lo expuesto anteriormente y con el propósito de reducir las dificultades que experimentan los estudiantes en el proceso de aprendizaje de la fisiología y mor-

\footnotetext{
${ }^{1}$ Colegio San Rafael Arcángel, Fundación Juan XXIII, Los Ángeles, Chile. https://orcid.org/0000-0002-0912-7994.

${ }^{2}$ Departamento de Medicina Interna, Facultad de Medicina, Universidad de La Frontera, Temuco, Chile. https://orcid.org/0000-0002-4835-7821.

${ }_{3}^{3}$ Departamento de Ciencias Básicas, Escuela de Educación, Campus Los Ángeles, Universidad de Concepción, Chile. https://orcid.org/0000-0001-9239-2344.

${ }^{4}$ Departamento de Física, Facultad de Ciencias, Universidad del Bío-Bío, Concepción, Chile. https://orcid.org/0000-0002-1564-3397.
} 
fología de la célula, el principal objetivo de este estudio fue determinar la influencia de la implementación de la metodología estaciones de aprendizaje como aprendizaje activo en los conocimientos y concepciones del concepto de la fisiología y morfología de la célula, respondiendo a las siguientes interrogantes:

¿Son las estaciones de aprendizaje una metodología más efectiva que la tradicional, para el aprendizaje de "teoría celular y célula procarionte" y "célula eucarionte y organelos"?, ¿Son las estaciones de aprendizaje una metodología de enseñanza y aprendizaje que influye positivamente en las concepciones del concepto de célula?, ¿Existe una relación directa entre los conocimientos adquiridos y las concepciones del concepto de célula? y, finalmente, ¿Cuál será la valoración de los alumnos respecto a la metodología de estaciones de aprendizaje aplicada?

\section{MATERIAL Y MÉTODO}

La investigación fue de tipo cuantitativa (Vieytes, 2004) y descriptiva (Hernández et al., 2010). El diseño metodológico se enmarcó dentro de las investigaciones cuasi experimentales (Tabla I) y la recolección de información se realizó antes y después de la intervención (Hernández et al., 2010).

La recolección de los datos se realizó aplicando instrumentos de medición validados por expertos. Dicha validación la realizaron académicos especialistas del área mediante la revisión y valoración de la pertinencia y claridad de cada test, incluyendo sus observaciones. Los instrumentos de recolección de información aplicados fueron tres, los cuales correspondieron a un Test de Concepciones, el cual se elaboró con 13 ítems de preguntas cerradas: selección múltiple, cuadro comparativo y verdadero y falso; un Test de Conocimientos adquiridos (Test 1 y 2), el cual contiene 18 preguntas de selección múltiple, distribuidas equitativamente para medir el logro del objetivo de cada estaciones de aprendizaje y una Encuesta de Valoración con 12 ítems (Encuesta 1), de los cuales 11 corresponden a preguntas semiestructuradas y una a pregunta abierta.

Los análisis se realizaron en el programa SPSS versión 25. Los resultados se trabajaron por medios descriptivos a través de tablas y figuras, para estos últimos se usó el programa GraphPad Prism versión 5.

Se utilizaron pruebas no paramétricas: Wilcoxon, U de Mann Whitney y correlación de Spearman (Cohen \& Manion, 1990; López \& Costa, 1996).

La muestra correspondió a dos cursos de enseñanza secundaria $(n=90)$, los cuales se seleccionaron de manera intencional (Zorrilla \& Torres, 1992). Las características de los estudiantes se presentan en la Tabla II.

Tabla II. Características de los Estudiantes

\begin{tabular}{|c|c|c|}
\hline $\mathbf{N}$ & $\begin{array}{c}\text { Grupo } \\
\text { Control } \\
45\end{array}$ & $\begin{array}{c}\text { Grupo Experimental } \\
45\end{array}$ \\
\hline Edad (años) & $15 \pm 1$ & $15 \pm 1$ \\
\hline \multicolumn{3}{|l|}{ Sexo } \\
\hline Masculino & 23 & 13 \\
\hline Femenino & 21 & 31 \\
\hline
\end{tabular}

La aplicación de la propuesta metodológica para el grupo experimental, constó de dos clases distribuidas en seis sesiones de 90 minutos. Por lo tanto, se planificaron las sesiones con dos estaciones de aprendizaje cada una, previamente diseñadas considerando el objetivo, contenido y procedimiento a desarrollar. Para cada sesión se dividió al azar al curso en 4 grupos de trabajo, por lo que se realizó cada estación dos veces y se entregó a cada alumno una guía de aprendizaje que debieron desarrollar en cada sesión según las estaciones correspondientes (Tabla III).

Las estaciones de aprendizaje planificadas se describen en la Tabla IV.

Tabla I. Diseño Cuasiexperimental.

\begin{tabular}{|c|c|c|c|c|}
\hline Grupo / medida & $\begin{array}{l}\text { Selección de } \\
\text { grupos }\end{array}$ & Pre test & Tratamiento & Post test \\
\hline Grupo Control & Asignado & Concepciones 0 & Metodología: “Clases & Concepciones \\
\hline \multirow[t]{2}{*}{ Grupo Experimental } & \multirow[t]{2}{*}{ Asignado } & \multirow[t]{2}{*}{ Concepciones 0} & $\begin{array}{l}\text { tradicionales" } \\
\text { Metodología: }\end{array}$ & $\begin{array}{c}\text { Test }_{1} \text { Test } 2 \\
\\
\\
\text { Concepciones }\end{array}$ \\
\hline & & & $\begin{array}{l}\text { "Estaciones de } \\
\text { aprendizaje" }\end{array}$ & $\begin{array}{c}\text { Test, } \\
\\
\text { Encue sta }{ }_{1} \text { Test }_{2}\end{array}$ \\
\hline
\end{tabular}

Concepciones 0: aplicado antes de la intervención.

Concepciones 1: aplicado después de la intervención.

Test 1: aplicado al final de la clase: "Teoría celular y célula procarionte".

Test 2: aplicado al final de la clase: "Célula eucarionte y organelos".

Encuesta 1: aplicado al final de la metodología. 
MARZUCA-NASSR, N.; MARZUCA-NASSR, G. N.; BARRIGA, A. A. \& SÁNCHEZ, S. I. R. Estaciones de aprendizaje para abordar concepciones de fisiología y morfología sobre el concepto de célula. Int. J. Morphol., 39(4):1015-1022, 2021.

Tabla III. Aplicación de la Metodología: Estaciones de Aprendizaje

\begin{tabular}{|c|c|c|c|c|c|c|c|c|}
\hline \multicolumn{9}{|c|}{ Clase 1: "Teoría celular y célula procarionte" } \\
\hline \multicolumn{3}{|c|}{ Sesión 1} & \multicolumn{3}{|c|}{ Sesión 2} & \multicolumn{3}{|c|}{ Sesión 3} \\
\hline Estación 1-A & $\begin{array}{l}\leftarrow \\
\leftarrow\end{array}$ & Estación 2-A & Estación 3-A & $\underset{\rightarrow}{\leftarrow}$ & Estación 4-A & Estación 5-A & $\underset{\rightarrow}{\leftarrow}$ & Estación 6-A \\
\hline Estación 1-B & $\underset{\rightarrow}{\leftarrow}$ & Estación 2-B & Estación 3-B & $\underset{\rightarrow}{\leftarrow}$ & Estación 4-B & Estación 5-B & $\underset{\rightarrow}{\leftarrow}$ & Estación 6-B \\
\hline
\end{tabular}

* Sesión: 90 minutos. *Estación: 30 minutos.

Clase 2: "Célu la eucarionte y organelos"

\begin{tabular}{|c|c|c|c|c|c|c|c|c|}
\hline \multicolumn{3}{|c|}{ Sesión 1} & \multicolumn{3}{|c|}{ Sesión 2} & \multicolumn{3}{|c|}{ Sesión 3} \\
\hline Estación 1-A & $\leftarrow$ & Estación 2-A & Estación 3-A & $\leftarrow$ & Estación 4-A & Estación 5-A & $\leftarrow$ & Estación 6-A \\
\hline Estación 1-B & $\underset{\rightarrow}{\leftarrow}$ & Estación 2-B & Estación 3-B & $\underset{\rightarrow}{\leftarrow}$ & Estación 4-B & Estación 5-B & $\underset{\rightarrow}{\leftarrow}$ & Estación 6-B \\
\hline
\end{tabular}

* Sesión: 90 minutos. *Estación: 30 minutos.

\section{RESULTADOS}

La Figura 1 muestra los resultados obtenidos en la aplicación de los Test de Conocimientos adquiridos para la clase 1 "Teoría Celular y Célula Procarionte" y la clase 2 "Célula Eucarionte y Organelos". Se realizaron las evaluaciones de forma simultánea al grupo control y al grupo experimental.

Siendo la comparación de ambos grupos en el Test $1(10,67 \pm 3,184$ vs $9,98 \pm 3,011 ; p=0,231) y$ en el Test $2(9,80 \pm 4,289$ vs $9,80 \pm 3,107 ; \mathrm{p}=0,957)$ sin diferencias significativas.

De los resultados obtenidos en la aplicación del Test de Concepciones del concepto de célula, que se midieron de forma simultánea al grupo control y al grupo experimental, se obtuvo la Figura 2, que muestra las concepciones del concepto de célula de los estudiantes antes y después de la intervención.

De la Figura 2, se infiere que al comparar ambos grupos antes de la intervención $(42,47 \pm 8,352$ vs 38,42 $\pm 8,625 ; \mathrm{p}<0,05)$ y después de la intervención $(51,61 \pm$ $10,341$ vs $49,84 \pm 9,114 ; p=0,237)$. Se establece que existen diferencias significativas antes de aplicar la propuesta metodológica (Figura 2A).

La Figura 3 muestra los resultados obtenidos, antes y después, de la comparación intragrupo de los Test de Concepciones del concepto de célula.

De la Figura 3 se deduce que el grupo control presentó un promedio de 42,47 $\pm 8,352$ antes de la intervención y 51,61 $\pm 10,341$ después de la intervención ( $\mathrm{p}<$ $0,001)$. Por otro lado, el grupo experimental presentó un
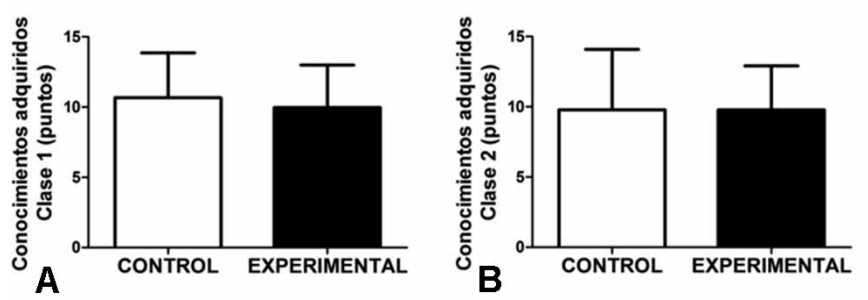

Fig. 1. Conocimientos adquiridos: Clase 1 y Clase 2. Los valores están presentados como promedio \pm desviación estándar. Los resultados fueron comparados utilizando la prueba estadística U de Mann-Whitney.
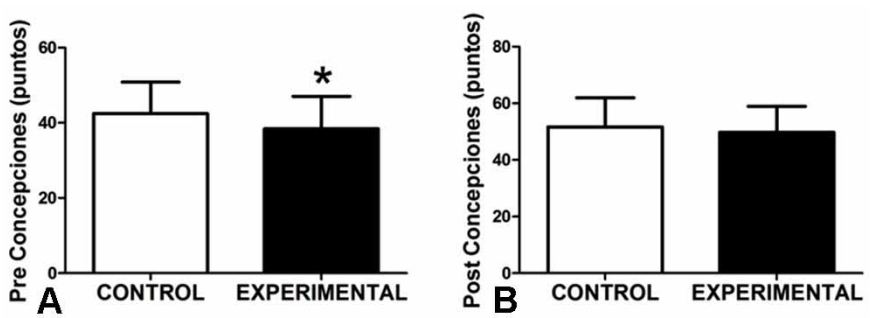

Fig. 2. Concepciones del concepto de célula, diferencias intergrupo. Los valores están presentados como promedio \pm desviación estándar. Los resultados fueron comparados utilizando la prueba estadística U de MannWhitney, $* \mathrm{p}<0,05$ (diferencia estadísticamente significativa).
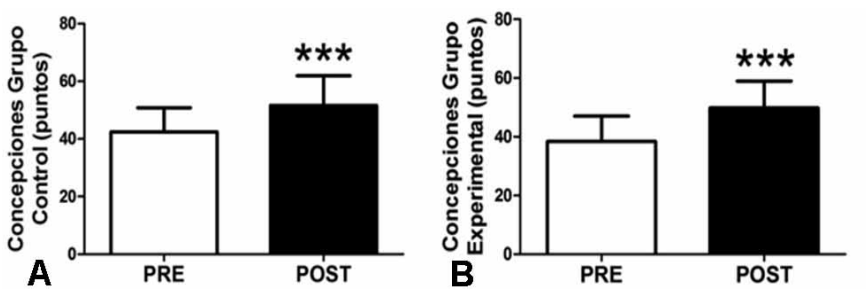

Fig. 3. Concepciones del concepto de célula, diferencias intragrupo. Los valores están presentados como promedio \pm desviación estándar. Los resultados fueron comparados utilizando la prueba estadística de Wilcoxon, $* * * \mathrm{p}<0,001$ (diferencia estadísticamente significativa). 
Tabla IV. Descripción de las Estaciones de Aprendizaje.

\begin{tabular}{|c|c|c|}
\hline \multicolumn{3}{|c|}{ Clase 1: "Teoría Celular y Célula Procarionte" } \\
\hline Estaciones & Objetivo & ción \\
\hline $\begin{array}{l}\text { 1. "Teoría celular: Video y } \\
\text { línea de tiempo" }\end{array}$ & $\begin{array}{l}\text { Reconocer el aporte de los científicos que } \\
\text { permitieron el desarrollo de la teoría } \\
\text { celular. }\end{array}$ & $\begin{array}{l}\text { de tiempo que considere } \\
\text { aportes hacia el desarrollo } \\
\text { celular. }\end{array}$ \\
\hline 2. "Microscopía" & $\begin{array}{l}\text { er la estructura y comprender el } \\
\text { niento del microscopio óptico. }\end{array}$ & $\begin{array}{l}\text { Los alumnos observan microscopios ópticos e } \\
\text { identifican cada una de sus partes con sus respectivas } \\
\text { funciones. Luego, los manipulan. }\end{array}$ \\
\hline $\begin{array}{l}\text { 3. "Postulados de la teoría } \\
\text { celular: } \\
\text { comprensiva" }\end{array}$ & $\begin{array}{l}\text { Aplicar en distintos ejemplos los } \\
\text { postulados de la teoría celular. }\end{array}$ & $\begin{array}{l}\text { Los alumnos deben leer distintos ejemplos de la } \\
\text { estructura, funcionamiento y origen de las células e } \\
\text { identificar a cuál postulado de la teoría celular } \\
\text { corresponde cada uno. }\end{array}$ \\
\hline $\begin{array}{l}\text { 4. "Célula Procarionte: } \\
\text { Estructura y función de una } \\
\text { bacteria" }\end{array}$ & $\begin{array}{l}\text { Comprender la morfología y fisiología de } \\
\text { una bacteria. }\end{array}$ & $\begin{array}{l}\text { de páginas web determinadas previamente, los } \\
\text { identifican y rotulan las partes de una bacteria } \\
\text { respectivas características y funciones. }\end{array}$ \\
\hline $\begin{array}{l}\text { 5. "Diferencias entre células } \\
\text { procariontes y células } \\
\text { eucariontes" }\end{array}$ & $\begin{array}{l}\text { Comprender las diferencias entre células } \\
\text { procariontes y células eucariontes. }\end{array}$ & $\begin{array}{l}\text { A p artir de la información de li bros de Biología } \\
\text { seleccionados previamente, los alumnos deben } \\
\text { comparar ambas células y completar un cuadro } \\
\text { comparativo destacando sus principales diferencias. }\end{array}$ \\
\hline $\begin{array}{lcl}\text { 6. “Teoría } & \text { celular, } & \text { célula } \\
\text { procarionte } & \text { vs } & \text { célula } \\
\text { eucarionte: } & & \text { Mapa } \\
\text { Conceptual” } & & \end{array}$ & $\begin{array}{l}\text { Sintetizar los contenidos de teoría celular, } \\
\text { célula procarionte y sus diferencias con la } \\
\text { célula eucarionte. }\end{array}$ & $\begin{array}{l}\text { Los alumnos deben elaborar un mapa conceptual que } \\
\text { resuma los contenidos abordados durante las } \\
\text { estaciones anteriores: teoría celular, célula procarionte } \\
\text { y sus diferencias con la célula eucarionte. }\end{array}$ \\
\hline
\end{tabular}

\begin{tabular}{|c|c|c|}
\hline \multicolumn{3}{|c|}{ Clase 2: "Célula Eucarionte y Organelos" } \\
\hline Estaciones & Objetivo & Descripción \\
\hline $\begin{array}{l}\text { 1. "Características } \mathrm{e} \\
\text { importancia de la célula } \\
\text { eucarionte" }\end{array}$ & $\begin{array}{l}\text { Reconocer las principales características } \\
\text { de la célula eucarionte. }\end{array}$ & $\begin{array}{l}\text { Los alumnos visualizan un video sobre las } \\
\text { características e i mportancia de la célula eucarionte, lo } \\
\text { que les permite responder un cuestionario. }\end{array}$ \\
\hline
\end{tabular}

2. "Estructura y Comprender la morfología y fisiología de
funcionamiento de la célula la célula eucarionte. eucarionte"

\begin{abstract}
3. "Comparación entre Comprender las diferencias entre células células Animales y eucariontes animales y vegetales.
\end{abstract} Vegetales"
A partir de páginas web determinadas previamente, los alumnos dibujan una célula eucarionte y rotulan sus principales organelos.

Los alumnos deben comparar imágenes o maquetas de ambas células y completar un cuadro comparativo destacando sus principales diferencias.

\begin{abstract}
4. "Características funcionamiento de organelos celulares"

5. "Fotosíntesis y respiración celular: Análisis de imágenes"

6. "Observación de células

6. "Observación de células
animales y vegetales" óptica.

Analizar muestras de células animales y vegetales mediante el uso de microscopía
\end{abstract}

y Con libros de Biología, previamente establecidos, los alumnos deben completar una tabla resumen sobre las características y fu ncionamiento de cada organelo celular.

Mediante el análisis de diferentes imágenes, los alumnos identifican la estructura de un cloroplasto y una mitocondria para comprender la relación funcional entre ambos organelos, lo que les permite responder preguntas de verdadero y falso.

Los alumnos visualizan a través de un microscopio óptico muestras de células animales y vegetales, las dibujan, rotulan y registran sus observaciones. promedio de 38,42 \pm 8,6252 antes de la intervención y 49,84 \pm 9,114 después de la intervención ( $p<0,001$ ). Evidenciando que existen diferencias significativas en ambos grupos.

Las Figuras 4 y 5 representan la correlación entre los conocimientos adquiridos por los estudiantes y las concepciones del concepto de célula; control y experimental, respectivamente.
De las Figuras 4 y 5 se deduce que existe una correlación estadísticamente significativa entre las variables analizadas. Además, se evidencia una correlación directa y positiva (grupo control: 0,762 y grupo experimental: 0,742) entre los conocimientos adquiridos y las concepciones del concepto de célula. 


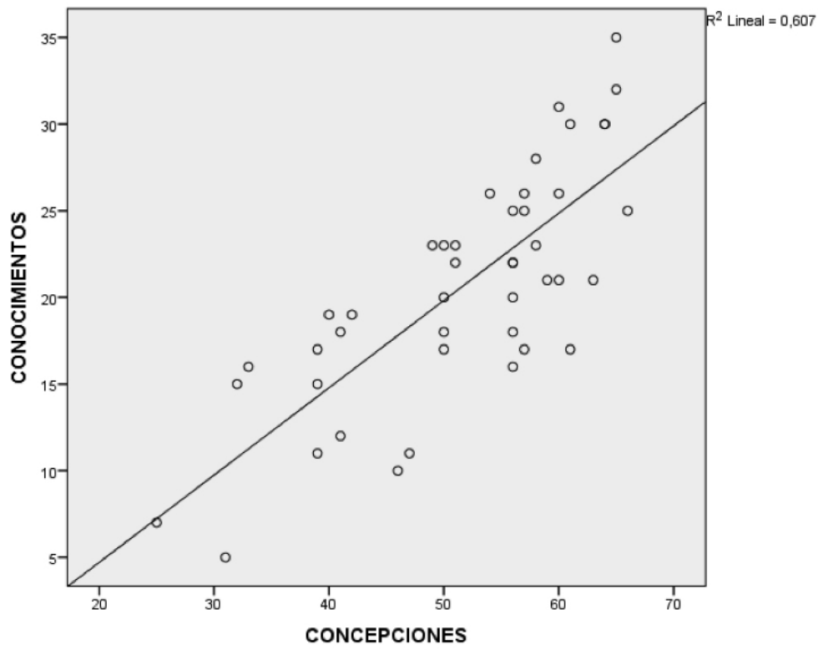

Fig. 4. Relación entre los conocimientos adquiridos y las concepciones del concepto de célula, Grupo Control. Los valores están presentados como puntaje. Los resultados fueron relacionados utilizando la prueba estadística correlación de Spearman, coeficiente de correlación $=0,762$. R2 $=0,607$.

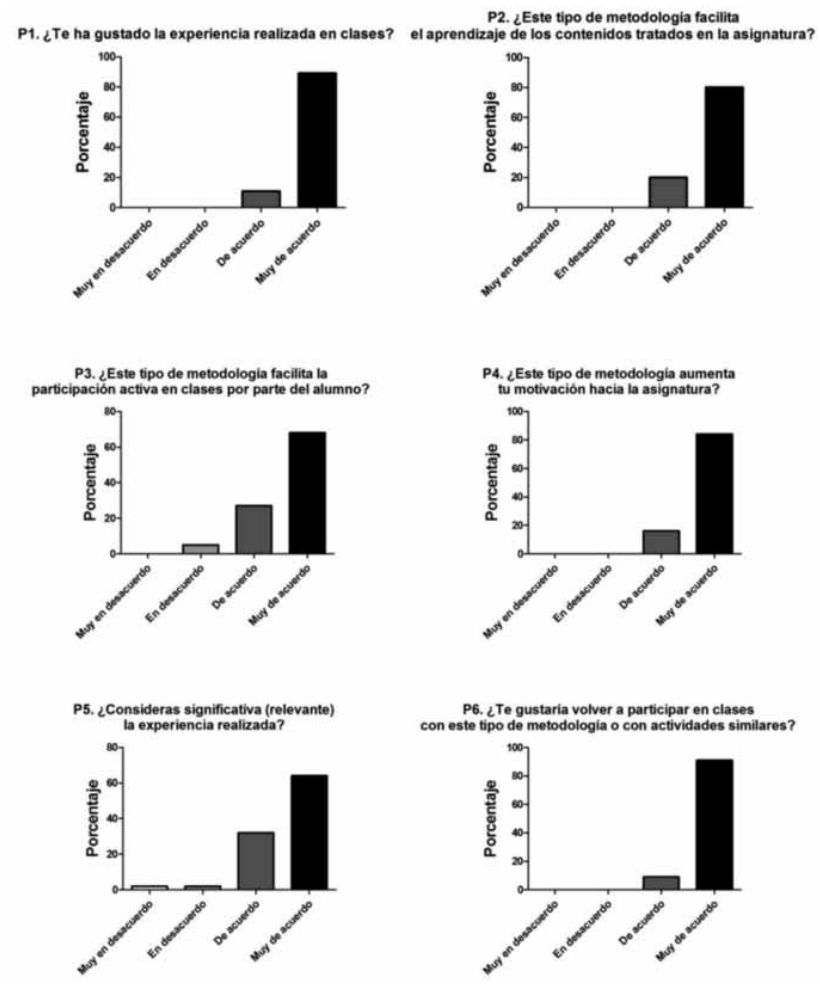

Fig. 6. Valoración de los estudiantes.

En la Figura 6 se muestra los resultados obtenidos de la encuesta de valoración, presentado en porcentajes, agrupado en cuatro categorías: Muy de acuerdo y De acuerdo (valoración positiva); En desacuerdo

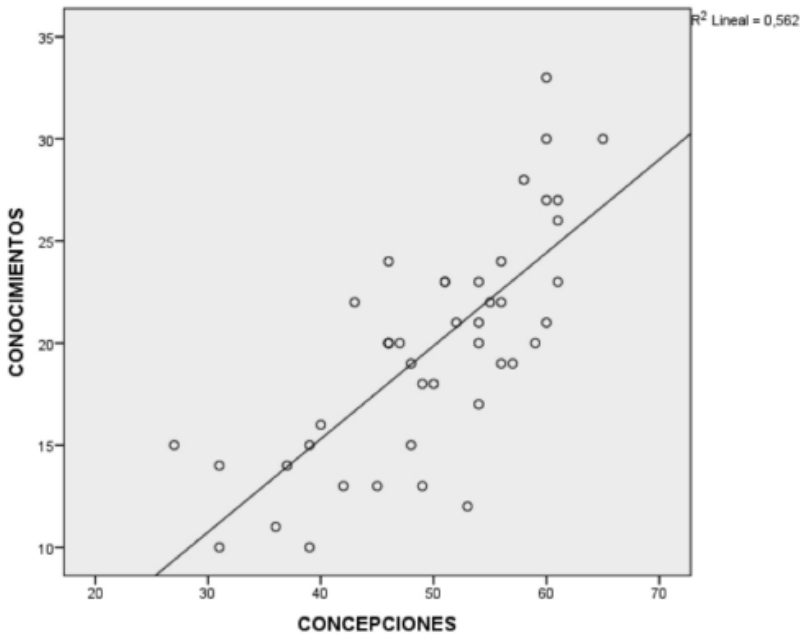

Fig. 5. Relación entre los conocimientos adquiridos y las concepciones del concepto de célula, Grupo Experimental. Los valores están presentados como puntaje. Los resultados fueron relacionados utilizando la prueba estadística correlación de Spearman, coeficiente de correlación $=0,742$. R2 $=0,562$.
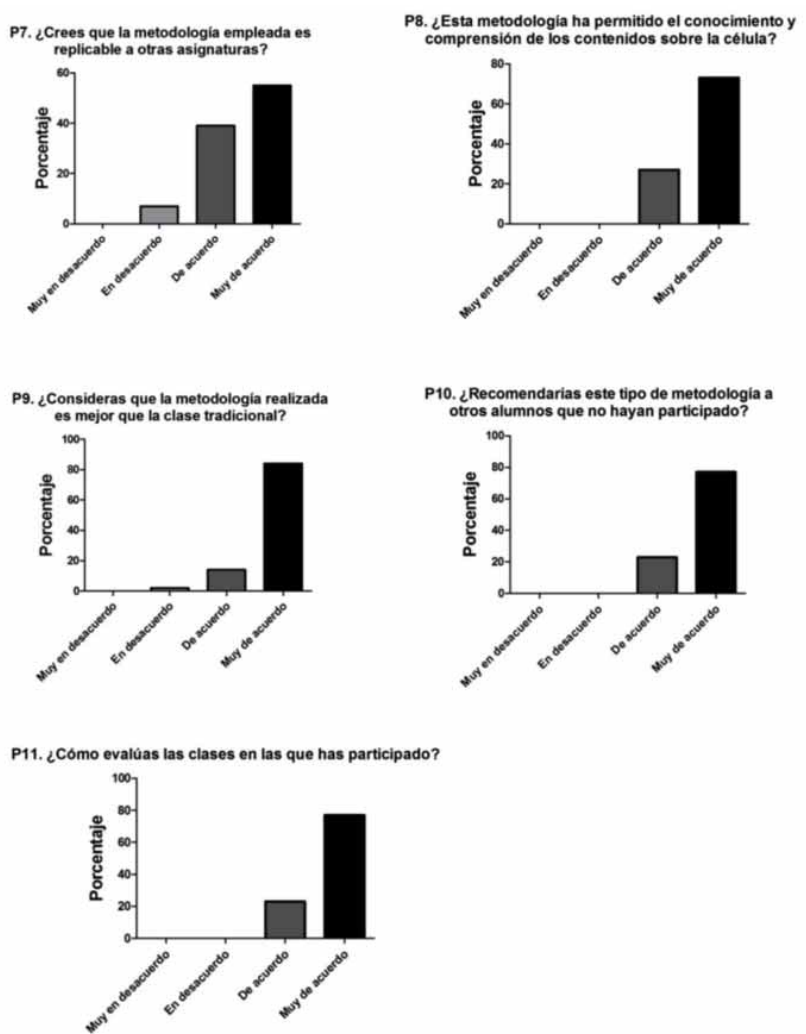

y Muy en desacuerdo (valoración negativa). En el que se observa la valoración realizada por los estudiantes sobre la propuesta metodológica y su experiencia de aprendizaje. 
De acuerdo a la Figura anterior, el $100 \%$ de los estudiantes señalan que les gustó la experiencia realizada en clases, consideran que la metodología facilita el aprendizaje de los contenidos tratados en la asignatura, permite el conocimiento y comprensión de los contenidos sobre la célula y aumenta la motivación de los estudiantes hacia la asignatura. También, indican que volverían a participar en clases con este tipo de metodología, la recomiendan a otros alumnos que no han participado y evalúan de manera positiva las clases en las que se aplicó la metodología de estaciones de aprendizaje.

Además, entre el $94 \%$ al $98 \%$ de los estudiantes considera que este tipo de metodología es replicable a otras asignaturas, facilita la participación activa en clases por parte del alumno, es una experiencia significativa y la califican como una metodología de aprendizaje activa mejor que la clase tradicional.

\section{DISCUSIÓN}

Los resultados arrojados permiten señalar que ambas metodologías poseen una efectividad sobre los conocimientos del concepto célula que adquieren los estudiantes, por lo que la metodología estaciones de aprendizaje no evidencia una ventaja de enseñanza aprendizaje sobre la metodología tradicional. Las razones de dicho resultado puede deberse a múltiples factores, entre los cuales se encuentra el no haber considerado al implementar la nueva metodología un periodo de adaptación a los cambios y requisitos por parte de los estudiantes, así como también evaluaciones coherentes con el estilo de metodología aplicada, es decir, privilegiar la evaluación del proceso por sobre una evaluación final cuantitativa que solo mide la valoración de conocimientos adquiridos, por lo que para futuras investigaciones se propone diseñar y aplicar instrumentos cualitativos, como listas de cotejo y rúbricas (Herrera \& Sánchez; Pegalajar, 2016).

Respecto a la medición de concepciones sobre el concepto de célula, antes de la intervención existía una diferencia estadísticamente significativa entre ambos grupos. Dichos resultados evidencian la complejidad que existe para los estudiantes aprender lo relativo a la célula (Rodríguez; Mengascini; Herrera \& Sánchez), ya que es un concepto abstracto, por lo que poseen una representación mental equivocada de ella (Caballer \& Giménez). Sin embargo, luego de la intervención se evidencia que no existen tales diferencias. En tal sentido, se establece que, a pesar de que el grupo experimental no supera al grupo control, la relación entre la metodología (estaciones de aprendizaje) aplicada permite que los estudiantes mejoren significativamente sus concepciones del concepto célula, ya que aumentaron su promedio en 11,42 puntos en comparación al grupo control que aumento en 9,14 puntos, lo que coincide con lo obtenido por Vieira \& Camero en el año 2004 al utilizar las estaciones de aprendizaje para el estudio de la materia, donde los resultados muestran una mejoría evidente en las concepciones previas de los estudiantes. En el mismo sentido, Baranzelli et al. (2018), al utilizar una propuesta educativa por estaciones para abordar el tema reproducción sexual en las plantas con flores, evidenciaron un incremento en el aprendizaje alcanzado por los estudiantes, ya que modificaron positivamente sus respuestas iniciales en todos los aspectos evaluados.

Por ello podemos decir que las estaciones de aprendizaje influyen positivamente en los conocimientos y concepciones del concepto de célula. Además, existe una correlación directa entre los conocimientos adquiridos y las concepciones del concepto de célula.

De acuerdo con la valoración de la percepción de los estudiantes respecto a la metodología aplicada, se establece que los criterios "De acuerdo" y "Muy de acuerdo" son de carácter positivo, lo que expresa que el $100 \%$ de los estudiantes considera que le gustó la experiencia realizada en clases y lo apoyan con comentarios como: "me encantaron las clases de biología con esta metodología" y "me gustó mucho este tipo de metodología, ya que es entretenida y dan ganas de seguir participando clase a clase", lo cual se asemeja a la valoración que hacen los estudiantes al ser sometidos a estaciones de aprendizaje para abordar la lengua extranjera, quienes calificaron la experiencia como satisfactoria (Espiñeira) y también a lo obtenido por la aplicación de otras metodologías de aprendizaje activo, donde los alumnos les gustó la experiencia realizada y la valoran como un entorno en el que pueden ocupar un papel activo, teniendo la oportunidad de construir su propio conocimiento (Larrán et al., 2013; Pegalajar). Además, la totalidad de los alumnos la valoran como una metodología que facilita el aprendizaje de los contenidos tratados en la asignatura, tal como lo obtenido por Larrán y colaboradores en el año 2013. Además, el $100 \%$ de los alumnos menciona que la metodología permite el conocimiento y comprensión de los contenidos sobre la célula, lo que apoyan con las siguientes opiniones: "fue muy productiva, nos permitió entender y comprender conceptos de biología" y "los medios audiovisuales, internet, libros y microscopía permiten aprender mejor y atender los diferentes estilos de aprendizaje", lo que se podría explicar porque este tipo de metodología ofrece otras posibilidades de aprendizaje (Espiñeira), lo cual es positivo porque las clases deben diversificar las instancias y estrategias que generen mayores posibilidades de acceso al conocimiento, mediante la oportunidad de participar en contextos flexi- 
bles y originales (Melgar \& Donolo). Sin embargo, lo anterior está sujeto a la capacidad de innovación de los docentes y al conocimiento que posean sobre distintas estrategias de enseñanza (Busquets et al., 2016). Por ello, aumentó la motivación de todos los estudiantes hacia la asignatura, lo cual se sostiene en comentarios como: "es muy bueno este tipo de metodología, motiva bastante, dan ganas de querer aprender y es algo fuera de lo común", lo que ocurre cuando los alumnos participan de metodologías activas de aprendizaje, generando mayor motivación para aprender (Larrán et al.; Busquets et al.) y se utilizan espacios como elementos didácticos, lo cual motiva y acrecienta una actitud positiva de los alumnos frente a las ciencias (PISA, 2003; Hernández et al., 2011). Lo que también se manifiesta en el interés de la totalidad de los estudiantes por volver a participar en clases con este tipo de metodología o con actividades similares, debido a que señalan que "para el alumno es más interesante, interactivo y entretenido hacer las clases de esta manera", tal como lo demuestra Espiñeira en el año 2005, donde la mayoría de los alumnos sostiene que les gustaría repetir la experiencia de estaciones de aprendizaje, debido a que "lo habían pasado bien, porque era muy diferente, nuevo, divertido, original, e interesante". Por tal razón, el $100 \%$ las recomiendan a otros alumnos que no han participado. En consecuencia, evalúan de manera positiva las clases en las que se aplicó dicha metodología y lo afirman agregando que "ayuda a la colectividad y no a la individualización de conocimientos", lo cual coincide con la aceptación de los estudiantes al ser evaluados mediante estaciones de aprendizaje (Companioni et al., 1999) y con otras metodologías de aprendizaje activo (Larrán et al.).

Además, entre el $94 \%$ al $98 \%$ de los estudiantes considera que este tipo de metodología es replicable a otras asignaturas, a modo de ejemplo: "me encantaría que todas las clases y materias fueran iguales, se podría aplicar la metodología en química, lenguaje e historia", debido a que facilita la participación activa en clases por parte del alumno, ya que manifiestan que "pudimos ser más participes en la clase, además nosotros buscábamos la información, lo que ayuda a comprender mejor", lo que se debe a que al utilizar modelos constructivistas de enseñanza se le otorga un papel activo al alumno en la construcción de su aprendizaje (Pozo, 1997; Campanario \& Aida, 1999; Hernández et al., 2011; Melgar \& Donolo). Lo anterior, posiciona a las estaciones de aprendizaje como una experiencia significativa, por lo que la califican como una metodología de aprendizaje activa mejor que la clase tradicional, ya que los estudiantes señalan: "es muy significativo y más entretenido aprender de este modo, las clases son más didácticas, no son rutinarias y fuera de lo tradicional" y "es mejor este tipo de metodología porque es más práctica, por lo que la clase tradicional es menos motivadora", lo que se justifica en que las metodologías tradicionales se caracterizan por presentar una enseñanza unidireccional (centrada en el docente), por lo que no favorecen al aprendizaje, interés ni motivación de los estudiantes (Pozo; Campanario \& Aida; Hernández et al., 2011; Busquets et al.).

En base a lo anterior, se concluye principalmente que respecto a los conocimientos adquiridos, las estaciones de aprendizaje no fueron una metodología de mayor efectividad en la clase: "Teoría Celular y Célula Procarionte", lo cual se justifica por la exposición a una nueva experiencia metodológica de aprendizaje, por lo mismo en la clase: "Célula Eucarionte y Organelos" las metodologías evaluadas poseen la misma efectividad. Además, la aplicación de la metodología estaciones de aprendizaje, permitió que los estudiantes (grupo experimental) lograran mejorar sus concepciones del concepto célula. En definitiva, las estaciones de aprendizaje influyen positivamente sobre los conocimientos y concepciones del concepto célula.También se pudo comprobar la existencia de una correlación significativa, directa y positiva, entre los conocimientos adquiridos y las concepciones del concepto de célula. Por otro lado, la valoración de los estudiantes respecto a la experiencia de aprendizaje de la cual fueron partícipes, es positiva y significativa.

Por último, la relevancia de la temática estudiada es que la metodología de enseñanza-aprendizaje: estaciones de aprendizaje es una propuesta válida y efectiva para los contenidos de célula tratados en Biología, lo cual permite lograr distintos objetivos de aprendizaje. En tal sentido, dicha metodología podría extrapolarse a otras temáticas, niveles, modos de evaluar y áreas de aprendizaje. Lo anterior, debido a que esta propuesta alternativa a la metodología tradicional permite a los estudiantes participar en contextos flexibles y trabajar cooperativamente. Además, diversifica las estrategias de enseñanza utilizadas, mediante distintos modos de presentación y representación, lo cual favorece al aprendizaje e incrementa el interés de los estudiantes, ya que centra su atención en el papel activo de ellos al construir su conocimiento.

MARZUCA-NASSR, N.; MARZUCA-NASSR, G. N.; BARRIGA, A. A. \& SÁNCHEZ, S. I. R. Learning stations to analyze physiology and morphology perceptions of cell concept. Int. J. Morphol., 39(4):1015-1022, 2021.

SUMMARY: The aim of this study was to determine the influence of the implementation and application of the learning stations teaching methodology on active learning of the physiology and morphology of the cell. We worked with 90 high school students, distributed in a control group and an experimental group, who received traditional classes and the application of the learning stations methodology, respectively. The data were collected based 
on a conception and knowledge test, plus an evaluation survey. The analysis of the data revealed that the learning stations are an effective teaching methodology in learning of the cell, since they allow to improve prior perceptions of the students, who significantly and positively value the methodology in which they participated.

KEY WORDS: Science teaching; Biology teaching; Cell concept; Teaching methodology; Learning stations.

\section{REFERENCIAS BIBLIOGRÁFICAS}

Acevedo, D.; Tirado, D. \& Montero, P. Perfil de aprendizaje y rendimiento académico en una asignatura de química en modalidad a distancia y presencial en dos programas de ingeniería. Form. Univ., 8 (6):39-46, 2015.

Baranzelli, M; Boero, L.; Córdoba, S.; Ferreiro, G.; Maubecin, C.; Paiaro, V.; Renny, M; Rocamundi, N.; Sazatornil, F.; Sosa-Pivatto, M.; et al. Socios por naturaleza: una propuesta didáctica para comprender la importancia de la interacción mutualista entre las flores y sus polinizadores. Enseñ. Cienc., 36(1):181-200, 2018.

Busquets, T.; Silva, M. \& Larrosa, P. Reflexiones sobre el aprendizaje de las ciencias naturales. Nuevas aproximaciones y desafíos. Estud. Pedag., 42:117-35, 2016.

Caballer, M. \& Giménez, I. Las ideas del alumnado sobre el concepto de célula al finalizar la educación general básica. Enseñ. Cienc., 11(1):63-8, 1993.

Campanario, J. \& Aida, M. ¿Cómo enseñar ciencias?. Principales tendencias y propuestas. Enseñ. Cienc., 17(2):179-92, 1999.

Cohen, L \& Manion, L. Métodos de Investigación Educativa. Madrid, La Muralla, 1990.

Companioni, F.; Bachá, Y.; Santos, P. \& Cabrera, M. Examen práctico estructurado por objetivos aplicado en ciencias morfológicas. Rev. Cuba. Educ. Med. Sup., 13(1):39-45, 1999.

Espiñeira, S. Una Aplicación de la Enseñanza Afectiva: Las Estaciones de Aprendizaje. Oviedo, Acta del XVI del Congreso de ASELE, 2005.

Hernández, R.; Fernández, C. \& Batista, L. Metodología de la Investigación. Ciudad de México, McGraw-Hill, 2010.

Hernández, V.; Gómez, E.; Maltes, L.; Quintana, M.; Muñoz, F.; Toledo, H.; Riquelme, V.; Henríquez, B.; Zelada, S. \& Pérez, E. La actitud hacia la enseñanza y aprendizaje de la ciencia en alumnos de Enseñanza Básica y Media de la Provincia de Llanquihue, Región de Los Lagos-Chile. Estud. Pedag., 37(1):71-83, 2011.

Herrera, E. \& Sánchez, I. Unidad didáctica para abordar el concepto de célula desde la resolución de problemas por investigación. Paradigma, 30(1):63-85, 2009.

Larrán, J.; Aparicio, J. \& López, A. Participación activa del alumno en prácticas de microscopía. Fund. Educ. Med., 16(4):233-7, 2013.

López B. \& Costa N. Modelo de enseñanza aprendizaje centrado en la resolución de problemas: fundamentación, presentación e implementación educativa. Rev. Enseñ. Cienc., 14(1):45-91, 1996.

Melgar, M. F. \& Donolo, D. S. Salir del aula...Aprender de otros contextos. Patrimonio natural, museos e internet. Rev. Eureka Enseñ. Divulg. Cienc., 8(3):323-33, 2011.

Mengascini, A. Propuesta didáctica y dificultades para el aprendizaje de la organización celular. Rev. Eureka Enseñ. Divulg. Cienc., 3(3):485-95, 2006.

Ministerio de Educación (MINEDUC). Habilidades de Pensamiento Científico: Decreto $N^{\circ} 254$. Santiago de Chile, Ministerio de Educación, Gobierno de Chile, 2009.
Motta, K. \& Uyaban, A. Caracterización de ideas previas sobre el concepto de ecosistema en estudiantes del grupo 505 del Colegio Minuto de Dios, ubicado en Ciudad Verde, Soacha Cundinamarca. Biografía. Escritos sobre la Biología y su Enseñanza, 43-52, 2016.

Pegalajar, M. Metodología docente y de evaluación en el nuevo espacio de convergencia europea para la formación del docente de Educación Secundaria. Estud. Pedag., 42(1):209-22, 2016.

Pinto, J. Métodos e instrumentos didácticos como mediadores del aprendizaje situado. Rev. Cient. CEPIES, 1(1):11-24, 2009.

PISA. Medida de los conocimientos y destrezas en matemáticas, lectura, ciencias y resolución de problemas. Madrid, OCDE, 2003.

Pozo, J. Enfoques para la Enseñanza de la Ciencia. Ed. Morata, 265308, 1997.

Rodríguez, M. La célula vista por el alumnado. Cienc. Educ., 9(2):229-46, 2003.

Rueda, E. \& Piraquive, R. La enseñanza del sistema digestivo y nutrición a través del enfoque de investigación dirigida. Biografía. Escritos sobre la Biología y su Enseñanza, 918-25, 2017.

Triviño, L. \& Tovar, E. Cambios conceptuales respecto a genética en estudiantes del grado $8^{\circ}$. Biografía. Escritos sobre la Biología y su Enseñanza, 681-688, 2017.

Vieira, A. \& Camero, R. Ejercicio práctico: "estaciones para el estudio de la materia". Investig. Postgrado, 19(1):79-97, 2004.

Vieytes, R. Metodología de la Investigación en Organizaciones, Mercado y Sociedad. Buenos Aires, Ed. de las Ciencias, 2004.

Zorrilla, S. \& Torres, M. Guía para Elaborar la Tesis. 2 ed. Ciudad de México, McGraw-Hill, 1992.

Dirección para correspondencia:

Nabil Marzuca-Nassr

Avenida Guillermo Marconi \# 773

Colegio San Rafael Arcángel

Los Ângeles

BíoBío

CHILE

E-mail: nabilmarzuca@gmail.com

Recibido : 16-04-2021

Aceptado: 14-05-2021 